Hierarchical dyadic congruence in family firms: The interplay of supervisor and supervisee socioemotional wealth importance and familial status

\author{
Giovanna Campopiano* \\ Witten Institute for Family Business (WIFU) \\ University of Witten/Herdecke \\ Alfred-Herrhausen-Straße 50 \\ 58455 Witten, Germany \\ E-mail: Giovanna.Campopiano@uni-wh.de
}

\author{
Emanuela Rondi \\ Free University of Bozen-Bolzano \\ Faculty of Economics and Management \\ Universitätsplatz 1 - Piazza Università, 1 \\ 39100 Bozen-Bolzano \\ E-mail: emanuela.rondi@unibz.it
}

ACCEPTED FOR PUBLICATION IN ENTREPRENEURSHIP THEORY \& PRACICE 15 th special issue on Theories of Family Enterprise

Author names are listed in alphabetical order (with all authors having contributed equally).

*Corresponding author 


\section{Hierarchical dyadic congruence in family firms: The interplay of supervisor and supervisee socioemotional wealth importance and familial status}

We extend McLarty, Vardaman, and Barnett's (in press) analysis of how family firm supervisor attributes, in terms of familial status and socioemotional wealth importance, affect supervisee performance by considering the supervisee attributes. We further integrate the concept of restricted and generalized social exchange to provide a theoretical basis for how hierarchical dyadic (in)congruence moderates the relationship between supervisee commitment and performance. By providing a more fine-grained conceptualization, we contribute to the family business literature at its organization behavior interface.

\section{Introduction}

McLarty et al. (in press) leverage social exchange theory and socioemotional wealth perspective to shed light on how the exchange between supervisor and supervisee in family firms affects supervisee performance. Their analysis focuses on the individual level concept of congruence emerging from the familial status and SEWi - the subjective value attributed by an individual to the stock of socioemotional wealth (Debicki, Kellermanns, Chrisman, Pearson, \& Spencer, 2016) - of the supervisor only and, as they point out (cf. footnote 2 and Limitations and Directions for Future Research), does not examine those of the supervisee. We show that incorporating the interplay of supervisor and supervisee familial status and SEWi in the hierarchical dyadic relationship refines the hypothesized effects on performance. Our propositions offer a more nuanced understanding about how social exchanges between family firm supervisors and supervisees affect performance at the individual worker level. We also provide a theoretical basis for analyzing the relationship between hierarchical dyadic congruence and performance grounded on the continuum between restricted and generalized forms of social exchange (Cropanzano \& Mitchell, 2005).

\section{Social Exchange Theory and Hierarchical Dyadic Congruence}

Recent research suggests a considerable variation in the extent to which family firm members aim to preserve socioemotional wealth (Miller \& Le Breton-Miller, 2014; Vandekerkhof, Steijvers, Hendriks, \& Voordeckers, 2017). Following this line of inquiry, McLarty et al. (in press) propose 
that supervisor (in)congruence would foster (hinder) supervisee motivation thereby, through (without) the resolution of goal dissonance, positively (negatively) affects the supervisees' commitment-performance relationship. We point out that there is a dyadic-level congruence between supervisor and supervisee that must also be considered because supervisee behavior does not depend only on the supervisor's attributes; instead, it depends additionally on the dyadic interaction between supervisor and supervisee attributes to shape the moderation effect on the commitment-performance relationship at the individual worker level.

Social exchange theory describes a relationship as a series of interactions interdependent on the actions of another person (Blau, 1964). At one end of the continuum, generalized social exchange, characterized by indirect reciprocity, exhibits itself in altruistic, collectivistic, cooperative, covenantal, trust-based, and intrinsically-motivated working relationships while, at the other end, restricted social exchange, characterized by limited reciprocity, results in individualistic, egoistic, self-interested, impersonal, and contractual relationships (Cropanzano \& Mitchell, 2005; Long \& Mathews, 2011). As the relationship moves along the continuum from generalized to restricted, it is characterized by lower degree of trust, support and solidarity and more utilitarianism (Uehara, 1990).

Considering both supervisor and supervisee attributes (in terms of familial status and high-low SEWi) at a dyadic level gives rise to the multiple configurations represented in Figure 1. Hierarchical dyadic congruence exists when the supervisor and supervisee have the same familial status and SEWi. If one or both attributes in the interaction differ, there is hierarchical dyadic incongruence. Hierarchical dyadic congruence and incongruence shape the relationship along the continuum between generalized and restricted form of exchange and norm of reciprocity, which drive the supervisee behavior. We argue that while hierarchical dyadic congruence always strengthens the supervisee commitment-performance relationship, 
hierarchical dyadic incongruence does not always place the relationship at the other extreme of the continuum. In other words, it does not necessarily weaken the supervisee commitmentperformance relationship.

\section{Hierarchical dyadic congruence: Supervisor and supervisee same attributes}

Hierarchical dyadic congruence in the form of same familial status and same high SEWi of the family firm supervisee and supervisor (both in Q1 in Figure 1) creates a strong bond within the family-oriented dyad (Vallejo, 2008) that promotes the generalized social exchange characterized by mutual trust and intrinsic motivation. On the other hand, hierarchical dyadic congruence in same familial status and same low SEWi (both in Q4) leads both supervisor and supervisee to prioritize the creation of financial wealth over the socioemotional one (Sciascia, Mazzola, \& Kellermanns, 2014; Ward, 1987) without harming the generalized social exchange. Therefore, in both cases, hierarchical dyadic congruence between supervisee and supervisor attributes will positively influence the commitment-performance relationship, fostering cooperation and trust.

Less intuitively, hierarchical dyadic congruence when both supervisor and supervisee are nonfamily members with high SEWi (both in Q2) can produce an agreement, despite the lack of blood ties between the individuals in the dyad, about which goals to focus, thus fostering the quality of their dyadic relationship (Miller \& Le Breton-Miller, 2014) and indirect reciprocity. Furthermore, the nonfamily supervisor-supervisee dyad with low SEWi (both in Q3) can interact as if they were involved in a nonfamily firm focusing on financial wealth, expecting lower benefits from socioemotional wealth preservation (Vardaman, Allen, \& Rogers, 2018). Therefore, in these two combinations, as well, the effect of supervisee commitment on performance is enhanced. Hence, we propose that:

P1: Hierarchical dyadic congruence between supervisor and supervisee in the family firm (Q1Q1, Q2-Q2, Q3-Q3, and Q4-Q4 combinations) strengthens the positive relationship between supervisee commitment and performance. 


\section{Hierarchical dyadic incongruence: When supervisor and supervisee attributes differ}

When the familial status of the two members of the dyad differ but the family member, whether supervisor or supervisee, has higher SEWi, a collectivistic, cooperative, and collaborative relationship is still possible through understanding about the parties' divergent interests, agreement about responsibilities, and the ensuing division of labor. The family member who benefits more from SEWi emphasizes both financial and socioemotional goals while the nonfamily member focuses on financial wealth creation (Vandekerkhof et al., 2017). In this intermediate form of social exchange along the continuum, indirect reciprocity is ensured by adherence to mutual expectations regarding SEWi blending diverse interests into a win-win situation (Le Breton-Miller, Miller, \& Lester, 2011). Therefore, we propose that:

P2: Hierarchical dyadic incongruence, when supervisor and supervisee differ in both familial status and SEWi with the family member having higher SEWi (Q1-Q3 combination), will not necessarily weaken the positive relationship between supervisee commitment and performance.

When the members of the dyad differ in familial status but have the same high SEWi, nonfamily members may still contribute to family firm culture, reputation and perceived amicability toward the family's continued control and influence (Tabor, Chrisman, Madison, \& Vardaman, 2018) so long as the nonfamily supervisors or supervisees perceive that they will be rewarded for helping to preserve socioemotional wealth (Deephouse \& Jaskiewicz, 2013). Conversely, when supervisee and supervisor with different familial status share low SEWi, both family and nonfamily member agree to focus on financial wealth creation (Vandekerkhof et al., 2017). Therefore, in both cases, although the relationship is based on contractualism and individual interests, there would be no conflict of interests or behavior and the complementary effects of working together will tend to nurture collectivism and boost cooperation. Thus:

P3: Hierarchical dyadic incongruence, when supervisor and supervisee differ in familial status but share the same high or low SEWi (Q1-Q2 and Q3-Q4 combinations), will not necessarily weaken the positive relationship between supervisee commitment and performance. 
When the members of the dyad share the same familial status but have different SEWi, conflicts will arise. In case both are family members, the lack of shared goals and shared values will generate disagreement (Carsrud, 2006). When both supervisor and supervisee are nonfamily members, but differ in SEWi, conflicts will emerge because the member that shows low SEWi will likely perceive the other as sycophantic (McLarty et al., in press), egoistic, and self-interest pursuing. This will endanger the legitimacy of the social exchange, limit reciprocity, and undermine the translation of supervisee commitment into performance. Therefore:

P4: Hierarchical dyadic incongruence, when supervisor and supervisee share familial status but differ in SEWi (Q1-Q4 and Q2-Q3 combinations), will weaken the positive relationship between supervisee commitment and performance.

When the members of the dyad differ in both familial status and SEWi, with low SEWi family members interacting with high SEWi nonfamily members, the two individuals prioritize inconsistent interests (Miller \& Le Breton-Miller, 2014). This situation is only logical if the nonfamily members, whether supervisors or supervisees, expect to be rewarded for pursuing socioemotional goals. But if family members with low SEWi are the supervisors, they would expect the nonfamily supervisees to focus only on financial wealth creation and would not appreciate the nonfamily members' devotion toward socioemotional goals. Presumably, the family supervisors would neither recognize nor reward them for whatever they accomplish, other than financial goals, to the extent expected by the nonfamily supervisees. On the other hand, if the supervisees are family members with low SEWi, they would wonder why socioemotional wealth should be so important to nonfamily supervisors - who would benefit less from the socioemotional stock - considering that it is not even important to themselves. In the worst case, family supervisees may be able to leverage their familial status to ignore or even belittle the nonfamily supervisors' SEWi emphasis. This will lead to disagreement, loss of status on the part of the nonfamily supervisors, and limited reciprocity (Miller, Le Breton-Miller, Minichilli, 
Corbetta, \& Pittino, 2014). Even when the family firm is professionalized, in the sense that nonfamily supervisors can impose penalties on the family supervisees, there could still be conflicts complicated by the possible interference of other family members.

In both situations, the non-family members will feel frustrated and conflicts will emerge as a result of unfulfilled expectations about the relationship between goal achievement and reward (Corbetta \& Salvato, 2004). Hence, the dyadic incongruence will tend to result in the limited reciprocity of restricted social exchange, creating dissonance in the supervisee about how to channel commitment into performance. Thus:

P5: Hierarchical dyadic incongruence, when supervisor and supervisee differ in both familial status and SEWi with the nonfamily member having higher SEWi (Q2-Q4 combination), will weaken the positive relationship between supervisee commitment and performance.

\section{Discussion and directions for future research}

McLarty et al. (in press) contribute a deeper understanding of the family firm supervisee commitment-performance relationship by investigating congruence in the social exchange between supervisor and supervisee, although ignoring supervisee attributes. We show that taking into account the interactions between the attributes of the members of the dyad limits the general applicability of their predictions with respect to incongruence. Instead, we propose that only in certain combinations of supervisor-supervisee attributes will hierarchical dyadic incongruence necessarily weaken the relationship between supervisee commitment and performance. Thus, we fill a conceptual gap at the family business-organization behavior interface (Gagné, Sharma, \& De Massis, 2014).

Second, while McLarty et al. (in press) only provide an intuitive connection between individual congruence and supervisee performance, we offer a conceptual foundation grounded in social exchange literature. Based on social exchange theory, we argue that only when the combination of supervisor-supervisee attributes results in restricted social exchange will the 
supervisee's commitment-performance relationship be weakened. In other words, the moderation effects caused by the dyadic attributes interplay, ranging from positive to negative, are consistent with the continuum from generalized to restricted social exchange (Long \& Mathews, 2011). In so doing, we show that social exchange theory, considered one of the most influential to investigate work relationships (Daspit, Holt, Chrisman, \& Long, 2016), can offer novel insights to our understanding about the family business phenomenon. Despite the conceptual limitations pointed out by our further analysis, however, McLarty et al. (in press) do provide empirical evidence about positive (negative by implication) moderation of the supervisee's commitmentperformance relationship by social exchange congruence (incongruence), though at the individual level instead of our dyadic level. This points out that the phenomenon may be more complex than either McLarty et al. (in press) or we, here, portray it.

This article also highlights the importance of dyadic constructs when examining family firm phenomena at the micro level. Neglecting them will fail to grasp the similarities and divergences of characteristics, opinions, and strategies within the same organization (e.g., Holt, Madison, \& Kellermanns, 2017). A logical step forward is to test these propositions empirically. Further conceptual developments include investigating the asymmetric nature of hierarchical dyadic congruence (Zhang, Wang, \& Shi, 2012) and considering how disparity - the diversity within the dyads emerging when one individual is superior to the other - depends on the position of the dyad in the family business organigram (Harrison \& Klein, 2007). The analysis of SEWi at a dyadic level can additionally be decomposed into its three dimensions (prominence, continuity and enrichment, Debicki et al., 2016) considering the distinct emphases placed by the two individuals in the hierarchical dyad. Future research adopting our framework can also examine the shaping role of hierarchical dyadic congruence on other relationships at the individual worker level in family firms, such as job satisfaction and turnover intention (Bernhard \& O'Driscoll, 
2011). Finally, scholars should analyze the evolution of individual attributes over time and their multilevel implications for the family and the business (Le Breton-Miller \& Miller, 2014).

\section{References}

Bernhard, F., \& O'Driscoll, M. P. (2011). Psychological ownership in small family-owned businesses: Leadership style and nonfamily-employees' work attitudes and behaviors. Group \& Organization Management, 36(3), 345-384.

Blau, P. M. (1964). Exchange and power in social life. New York: John Wiley.

Carsrud, A. L. (2006). Commentary: "Are we family and are we treated as family? Nonfamily employees' perceptions of justice in the family firm": It all depends on perceptions of family, fairness, equity, and justice. Entrepreneurship Theory and Practice, 30(6), 855-860.

Corbetta, G., \& Salvato, C. (2004). Self-serving or self-actualizing? Models of man and agency costs in different types of family firms: A commentary on "comparing the agency costs of family and non-family firms: Conceptual issues and exploratory evidence". Entrepreneurship Theory and Practice, 28(4), 355-362.

Cropanzano, R., \& Mitchell, M. S. (2005). Social exchange theory: An interdisciplinary review. Journal of Management, 31(6), 874-900.

Daspit, J. J., Holt, D. T., Chrisman, J. J., \& Long, R. G. (2016). Examining family firm succession from a social exchange perspective: A multiphase, multistakeholder review. Family Business Review, 29(1), 44-64.

Debicki, B. J., Kellermanns, F. W., Chrisman, J. J., Pearson, A. W., \& Spencer, B. A. (2016). Development of a socioemotional wealth importance (SEWi) scale for family firm research. Journal of Family Business Strategy, 7(1), 47-57.

Deephouse, D. L., \& Jaskiewicz, P. (2013). Do family firms have better reputations than nonfamily firms? An integration of socioemotional wealth and social identity theories. Journal of Management Studies, 50(3), 337-360.

Gagné, M., Sharma, P., \& De Massis, A. (2014). The study of organizational behaviour in family business. European Journal of Work and Organizational Psychology, 23(5), 643-656.

Harrison, D. A., \& Klein, K. J. (2007). What's the difference? Diversity constructs as separation, variety, or disparity in organizations. Academy of Management Review, 32(4), 1199-1228.

Holt, D. T., Madison, K., \& Kellermanns, F. W. (2017). Variance in family members' assessments: The importance of dispersion modeling in family firm research. Family Business Review, 30(1), 61-83.

Le Breton-Miller, I., \& Miller, D. (2014). Temporal considerations in the study of family firms: Reflections on "the study of organizational behaviour in family business". European Journal of Work and Organizational Psychology, 23(5), 669-673.

Le Breton-Miller, I., Miller, D., \& Lester, R. H. (2011). Stewardship or agency? A social embeddedness reconciliation of conduct and performance in public family businesses. Organization Science, 22(3), 704-721.

Long, R. G., \& Mathews, K. M. (2011). Ethics in the family firm: Cohesion through reciprocity and exchange. Business Ethics Quarterly, 21(2), 287-308.

McLarty, B. D., Vardaman, J. M., \& Barnett, T. (in press). Congruence in exchange: The influence of supervisors on employee performance in family firms. Entrepreneurship Theory and Practice.

Miller, D., \& Le Breton-Miller, I. (2014). Deconstructing socioemotional wealth. Entrepreneurship Theory and Practice, 38(4), 713-720. 
Miller, D., Le Breton-Miller, I., Minichilli, A., Corbetta, G., \& Pittino, D. (2014). When do nonfamily CEOs outperform in family firms? Agency and behavioural agency perspectives. Journal of Management Studies, 51(4), 547-572.

Sciascia, S., Mazzola, P., \& Kellermanns, F. W. (2014). Family management and profitability in private family-owned firms: Introducing generational stage and the socioemotional wealth perspective. Journal of Family Business Strategy, 5(2), 131-137.

Tabor, W., Chrisman, J. J., Madison, K., \& Vardaman, J. M. (2018). Nonfamily members in family firms: A review and future research agenda. Family Business Review, 31(1), 54-79.

Uehara, E. (1990). Dual exchange theory, social networks, and informal social support. American Journal of Sociology, 96(3), 521-557.

Vallejo, M. C. (2008). Is the culture of family firms really different? A value-based model for its survival through generations. Journal of Business Ethics, 81(2), 261-279.

Vandekerkhof, P., Steijvers, T., Hendriks, W., \& Voordeckers, W. (2017). Socio-emotional wealth separation and decision-making quality in family firm TMTs: The moderating role of psychological safety. Journal of Management Studies.

Vardaman, J. M., Allen, D. G., \& Rogers, B. L. (2018). We are friends but are we family? Organizational identification and nonfamily employee turnover. Entrepreneurship Theory and Practice, 42(2), 290-309.

Ward, J. (1987). Keeping the family business healthy: How to plan for continuing growth, profitability, and family leadership. San Francisco: Joessy Bass.

Zhang, Z., Wang, M., \& Shi, J. (2012). Leader-follower congruence in proactive personality and work outcomes: The mediating role of leader-member exchange. Academy of Management Journal, 55(1), 111-130. 
Figure 1. Framework for hierarchical dyadic congruence and incongruence as combination of supervisor and supervisee familial status and SEWi
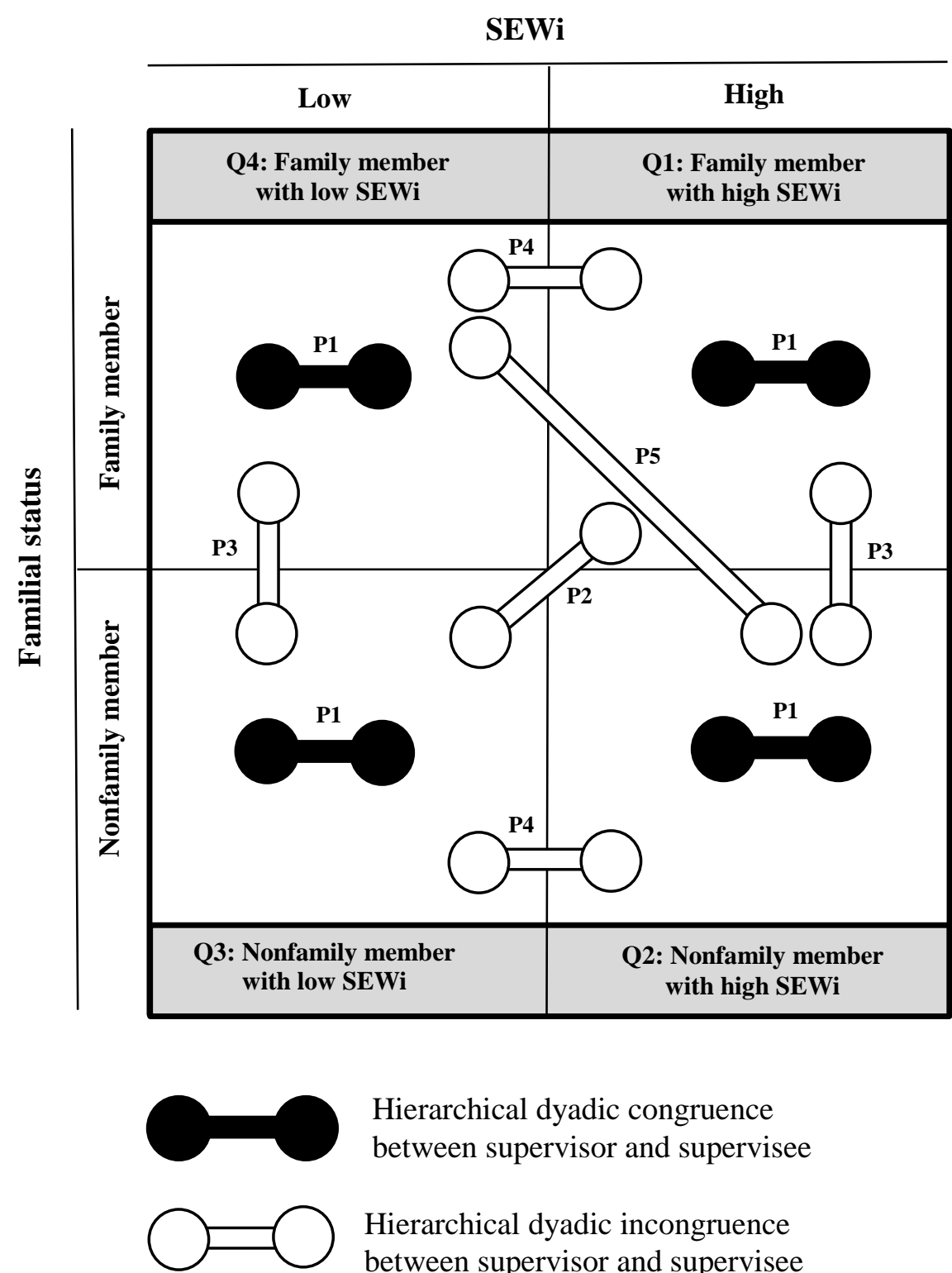

Hierarchical dyadic congruence

between supervisor and supervisee

Hierarchical dyadic incongruence

between supervisor and supervisee 